Journal of the

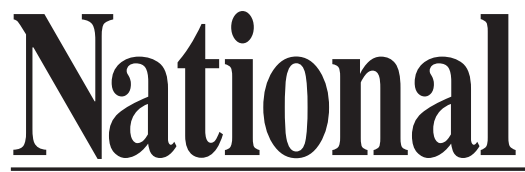

Academy or

Forensic
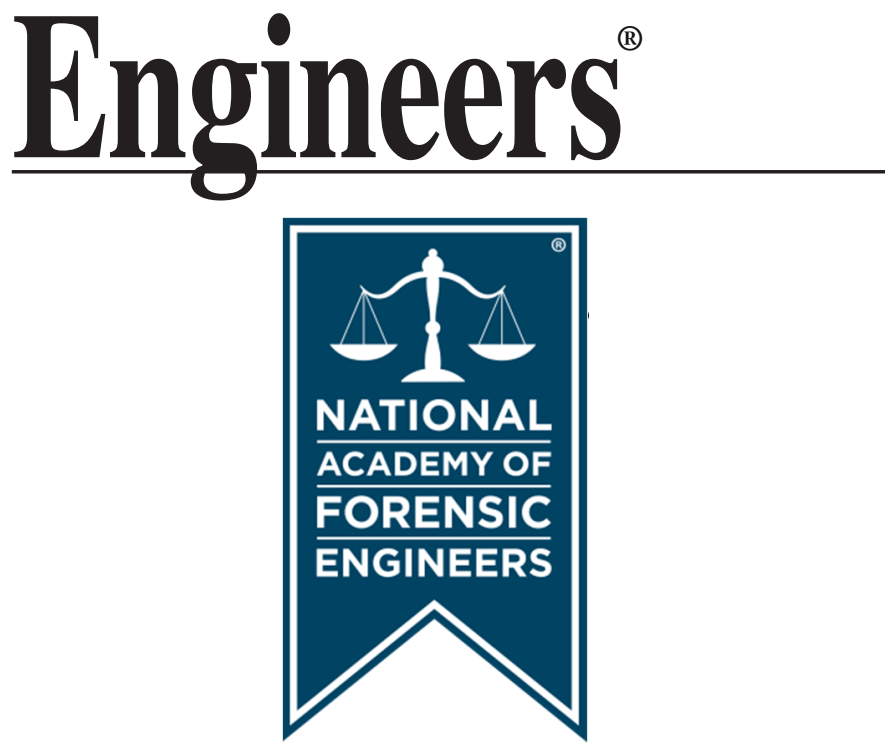

http://www.nafe.org

ISSN: 2379-3252

Vol. XXIII No. 2 December 2006 


\title{
Forensic Engineering Analysis of Codes Causative of Building Envelope Failures
}

\author{
by Geoffrey G. Jillson P.E. (NAFE 429S)
}

\section{Introduction}

Moisture intrusion and accumulation in the building envelope causes conditions of deterioration including development of mold which form the basis of numerous lawsuits. The causes of intrusion of moisture/water into the envelope relate to materials and construction methods which in turn may relate to one or multiple subcontractors or suppliers on a project. Any of the contractors, subcontractors, suppliers or product manufacturers may and commonly are parties in complex litigations involving damage in the building envelope. The involved parties commonly include the General Contractor, Architect, Engineer/s, masonry subcontractors, HVAC subcontractor, window manufacturer, window vendor, framer/window installer, roofer, siding subcontractor, insulation subcontractor etc.

Issues relating to conformity with "in-force" building codes at the time of construction are nearly always key elements in litigations with the common assumption that code conformance equals good construction and therefore is not causal to the problems with the building envelope and conversely that if a code provision is violated or not fully adhered to that the construction is deficient and causal to the problems with the building envelope. These two assumptions have been shown in certain critical areas to not be valid. Conformance with certain provisions of the Building codes and Energy codes as required by licensing laws in most states for both design professionals and contractors have proven to be causal to problems with moisture intrusion and accumulation and deterioration of the building envelope. Thus contractors building to the provisions of the codes are building in some aspects to flawed formulas which are causal to the problem. Understanding the conflicts in the codes which cause the problem will assist experts providing services in such litigations. Evaluation of liability of certain parties and apportionment of liability may be affected when it is shown that the design and/or construction met code requirements but that the code provisions, rather than workmanship, were contributory or causal to the damage.

Building codes created and maintained for the purpose of protecting people and property have existed in various forms for millennia. The codes were intended to result in standards of construction which reduced hazards from fire 
and collapse and as time went by to improve aspects of safety. It cannot be argued that building codes have had very positive effects. It is rare in the west, even during earthquakes, to see building collapses and injury. Fires in cities are usually contained with little loss of life. Code provisions for hurricane resistant construction are now highly refined and effective. Trends in improvements of building codes have been gradual and continuous over time. Changes in the codes in recent years have been occurring at ever more accelerated rates with frequent and substantial alterations and technical specificity. Building Codes have become more homogenized with common codes put forth by such groups as the non-governmental corporation "International Conference of Building Officials" (ICBO) commonly adopted by the various states with local alterations and amendments. Building codes at state levels are typically comprised of multiple documents usually taken from national models which include the Uniform Building Code, Uniform Mechanical Code, Uniform Fire Code, Uniform Plumbing Code, National Electric Code and more recently the Handicapped Accessible Codes, all with various revisions. These codes are revised periodically at non uniform times and are adopted by the individual states at non uniform times, perhaps with local amendments, but have generally evolved gradually, empirically and with specificity.

In 1983 the United States Department of Energy (DOE) funded the first version of the "Model Energy Code" developed jointly by Building Officials and Code Administrators International (BOCA), International Conference of Building Officials (ICBO), National Conference of States on Building Codes and Standards (NCSBCS) and Southern Building Code Congress International (SBCCI). The Model Energy Code was adopted in many states and subsequently incorporated either by reference or rewrite into the State Building Codes. The stated intent of the "Model Energy Code" is as follows:
"The provisions of this code shall regulate the design of building envelopes for adequate thermal resistance and low air leakage and the design and selection of mechanical, electrical, service water heating and illumination systems and equipment which will enable effective use of energy in new building construction."

In practical terms, the energy code effected changes in three basic areas; insulation levels, sealing of the building envelope and implementation of more efficient appliances, principally heating and cooling equipment. Although promulgated as a regulatory document, the energy code, rather than providing only performance standards also contains prescriptive code similar to that found in the building codes. Such elements would perhaps be better placed in the appropriate sections of building codes rather than in a regulatory document. Some provisions such as vapor barrier, air leakage barrier and weather resistive barrier 
are conceptual and in places conditional which has led to confusion and misapplications by contractors and building officials.

The introduction of the Model Energy Code, by comparison with the traditional building codes, has been revolutionary, global and conceptual. Interpretation and application of the energy code has occurred in the midst of myriad of new synthetic building materials and construction techniques in a mix with traditional organic materials and construction methods. Some unwanted and unforeseen effects have resulted. Prior to the implementation of the Model Energy Code, matters litigating construction defects relating to moisture intrusion and accumulation with associated deterioration in structures were comparatively few. Post Energy Code and at publication of this paper, literally thousands of active cases involving these issues are pending and case law is unsettled.

This paper summarizes some of the main areas of conflict in the energy codes and building codes and adverse effects which result. The work reflects evaluations of hundreds of structures using invasive, non invasive and remote sensing techniques which have been ongoing by the writer for many years combined with mathematical modeling of energy flux and moisture content in wall sections using computer methods. General areas in which problems arise are presented below.

\section{Insulation}

The primary way in which energy savings has been effected through the energy code is by increased insulation levels. Two basic methods are provided;

The prescriptive criteria (cookbook) method; Minimum insulation levels of walls, floors, ceilings and windows and doors are met specifically. "In ceilings with attics, insulation must be R-38 with improved or advanced framing or R44 without improved or advanced framing. In ceilings without attics, insulation must be $\mathrm{R}-38$ between framing plus $\mathrm{R}-5$ sheathing." Improved ceiling framing requires a minimum of $7-1 / 2$ inches between the wall top plate and the roof sheathing. Advanced ceiling framing means full ceiling insulation levels carried to the vertical line of the exterior wall. Advanced wall framing means $2 \times 6$ stud spacing set 24 inches on center with insulated headers, "two-stud corners using approved backing for the attachment of facing materials, full insulation wherever possible between partition wall intersections with exterior walls, and, when foam insulated sheathing is used, replacement of cripples with hangars whenever possible." The above methods are examples of specific code type provisions and are common.

The alternative method is called the "performance method". In this method an overall $\mathrm{U}$ factor for the wall assembly with windows and doors must be less 
than $0.11 \mathrm{Btu} / \mathrm{hr} \cdot \mathrm{ft}^{2} \cdot{ }^{\circ} \mathrm{F}$, roof/ceilings $\mathrm{U}$ factor less than $0.026 \mathrm{Btu} / \mathrm{hr} \cdot \mathrm{ft}^{2} \cdot{ }^{\circ} \mathrm{F}$ and floors $\mathrm{U}$ factor less than $0.04 \mathrm{Btu} / \mathrm{hr} \cdot \mathrm{ft}^{2} \cdot{ }^{\circ} \mathrm{F}$. This method allows for adjustment of the variables of walls, windows and insulation levels to achieve overall performance of the wall or roof/ceiling or floor area.

The essence of the alternative framing methods is to dramatically increase the wall insulation levels. In practical terms the advanced method allows for slightly increased window area. The most common construction is $2 \times 6$ studs set on 16 inch centers. Advanced wall framing is rarely used in the upper Midwest.

The practical effect of either method is that walls are now constructed almost exclusively with $2 \times 6$ studs with sheathing having insulation levels less than R-5, and standard fill fiberglass insulation in wall cavities. The construction eliminates the requirement for foam sheathing and has proven to be a cost effective and straightforward construction method. Ceilings are typically constructed with R-44 insulation. The result compared with $2 \times 4$ stud walls is increased wall insulation levels of approximately $50 \%$. Heat flux through the wall assembly has been sharply reduced. Temperature levels on sheathing and within the wall assembly have dropped as a result. Calculations were made using computer methods which show the anticipated temperatures as shown in the graph "Heat Flux Through Wall."

Attic conditions and under floor conditions in the building code are required to be ventilated, however, walls in the building envelope are not required by current codes to be ventilated. Adverse effects of highly insulated walls focused expressly on reducing heat flux through the wall assembly combined with sealing of various surfaces within the envelope in conjunction with various new no-maintenance building products has resulted in introduction of and accumulation of moisture in the building envelope. The greatly reduced heat flux through the building envelope combined with limited and localized specialty sealing of some but not all elements in the envelope as required in versions of the energy code has resulted in an overall combined code formula of the energy code and building codes with no interaction which creates pathways conducting moisture laden air into partially sealed building envelopes which are below dew point temperatures, thus resulting in chronic wetting, deterioration and failure of the building envelope.

\section{Heat Flux Analysis}

Heat flux through the wall assembly was calculated using computer programs and by manual methods. Heat flux is expressed as Btu/hr. $\mathrm{ft}^{2} \cdot{ }^{\circ} \mathrm{F}$. Flux for an R-13 insulation level wall was calculated based upon the theoretical performance of a standard stud wall with stud thickness or wall cavity depth of 3.5 inches. The wall assembly was constructed from the interior to the exterior is as 
follows: $1 / 2$ inch thick layer gypsum wall board, 4 mil polyethylene vapor barrier, wall cavity (3.5 inch depth) filled with standard density fiberglass batt insulation, $5 / 8$ inch thick fiberboard sheathing, 15 pound felt paper (weather resistive barrier), and $3 / 4$ inch thick hard coat stucco. $U$ factors for each material in the assembly were calculated. The calculations were based upon ASHRAE data for conditions in the Minneapolis, Minnesota area with a northern exposure wall which field observations have shown to have the greatest likelihood for deterioration. Interior temperature was set at $68 \mathrm{deg} \mathrm{F}$.

It should be noted that the theoretical R-13 insulation value for standard filled $2 \times 4$ stud wall is in practical terms excessively high. Due to construction realities in the use of kraft backed or foil backed insulation as compared with friction fit insulation and corresponding installation techniques, the actual insulation values of kraft backed and foil backed R-13 insulation are actually substantially lower, perhaps as much as $\mathbf{3 0}$ percent. This results from gaps typically appearing at stud areas due to installation of the insulation. R-19 insulation values by comparison reflect closely the actual practical field conditions. This results from changes in installation practice and almost uniform use of friction fit insulation with roll type polyethylene vapor barrier as compared with kraft backed or aluminum backed R-19 rolls or batts. As a result, the insulation fill in the cavities in a practical sense is nearly complete. Due to these construction realities, therefore, the data actually reflect less heat flux through the standard filled $2 \times 4$ stud wall than actually occurs as compared with the R-19 data which reflect the more closely actual as-built conditions. The data are presented in a

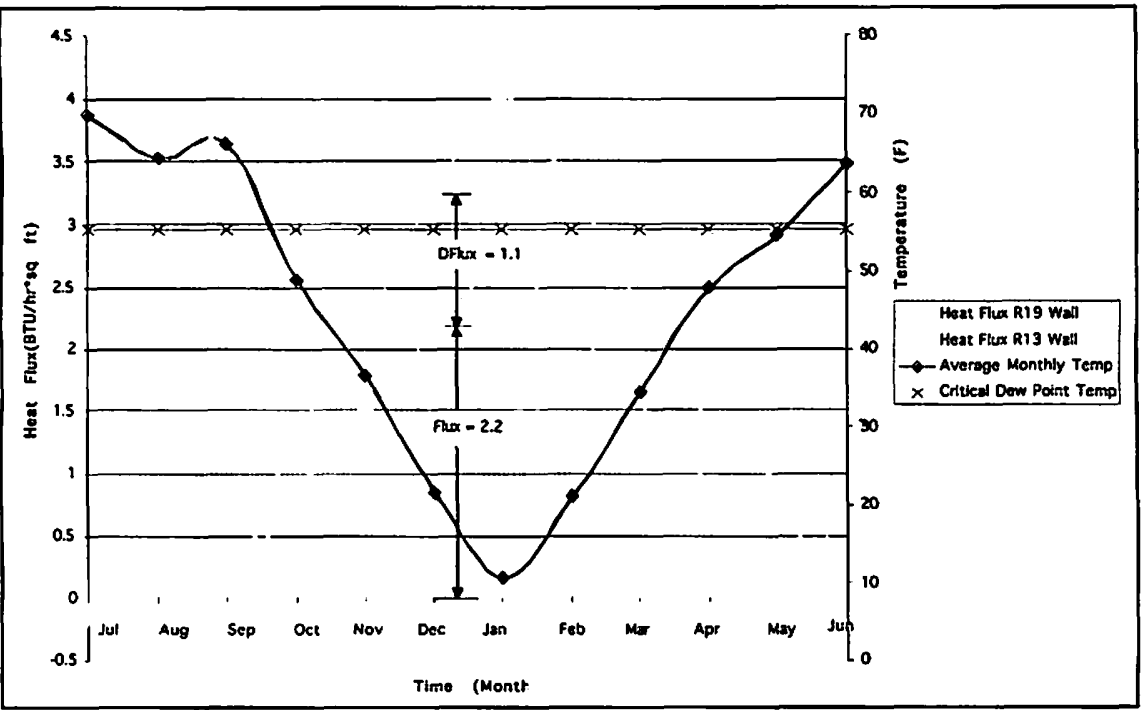

Heat Flux Through Wall 
graph displaying the calendar year along the abscissa, heat flux expressed in $\mathrm{Btu} / \mathrm{hr} \cdot \mathrm{ft}^{2} \cdot{ }^{\circ} \mathrm{F}$ on the left ordinate and temperature in degrees Fahrenheit along the right ordinate. January 1st was set at the center of the graph for purposes of graphical simplicity and interpretation. The data generally show a heat flux decrease with the R-19 wall compared with the R-13 wall cavity of approximately 50 percent. The graph shows that the area between the curves of the $R$ 19 wall heat flux versus the R-13 heat flux is substantial and that the differential extends over a long period of time.

Field observations of wall cavities and sheathing conditions observed on hundreds of wood frame residential structures made with invasive penetrations from the exterior and interior during all calendar months of the year have revealed generally wet conditions during the colder months and frozen sheathing and ice/frost on interiors of wall cavities commonly in winter months. The data presented in the above graph reflect the actual conditions observed in the field. These conditions appear to have been unforeseen by promulgators of the energy code.

\section{Temperature in Wall Cavity}

The average temperatures at the interior of sheathing and at the interior of the sheetrock are calculated for the same wall assembly as was used for the humidity calculations shown above and also for a north exposure wall. Note that temperatures at the sheathing layer during the winter months are at or below freezing level of $32 \mathrm{deg} F$ for extended periods. This is consistent with field observations which often reveal ice or frost on the interior surface of the sheathing layer within the wall cavity. The analysis is based upon water vapor present

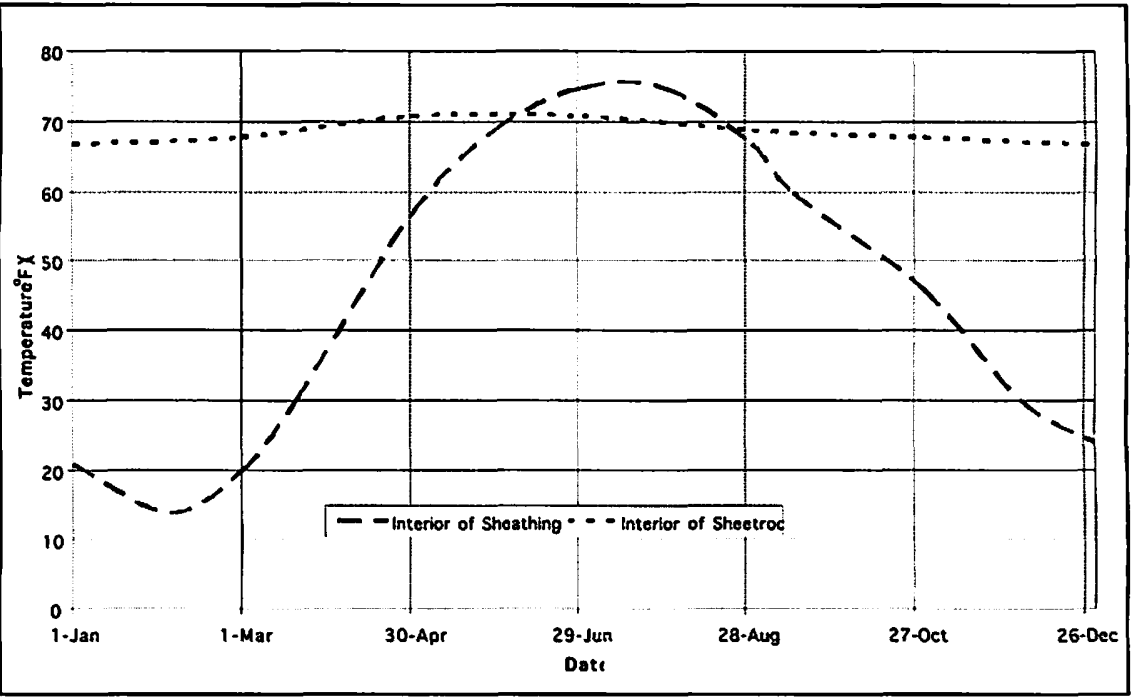


on the exterior permeating through the hard coat stucco and moisture communicated from the habitable space through the gypsum wall board. As shown in the graph showing the temperatures in the wall cavity compared with the relative humidity levels, it is readily seen that intrusion of moisture into the wall cavities will result in condensation within the wall cavities.

\section{Humidity in Wall Cavity}

Modeling of relative humidity within the wall cavity and temperature in the wall cavity were performed utilizing a $2 \times 6$ standard construction fiberglass fill wall cavity with hard coat stucco. The graph presented shows the interior surface of the exterior sheathing within the wall cavity. This is shown with the calendar days on the abscissa and the relative humidity expressed on the left ordinate. The graph also shows the surface of the gypsum wall board on the interior of the habitable space. The days are expressed numerically with day 0 as January 1 st and increasing to the right. The actual relative humidity level on the interior should be assumed to be continuous with the right hand portion of the curve at day 365. The data are computed for Minneapolis, Minnesota for a north exposure wall as described above. Note that relative humidity at exterior sheathing layer in the wall cavity remains high (above $70 \%$ rh throughout the year) even though large variations in interior humidity occur. This demonstrates that the poly vapor barrier is quite effective at blocking moisture migration into the wall cavity from the interior of the habitable space.

It should be noted that the model reflects a pure section of wall and excludes anomalies and discontinuities of the vapor barrier at penetrations and

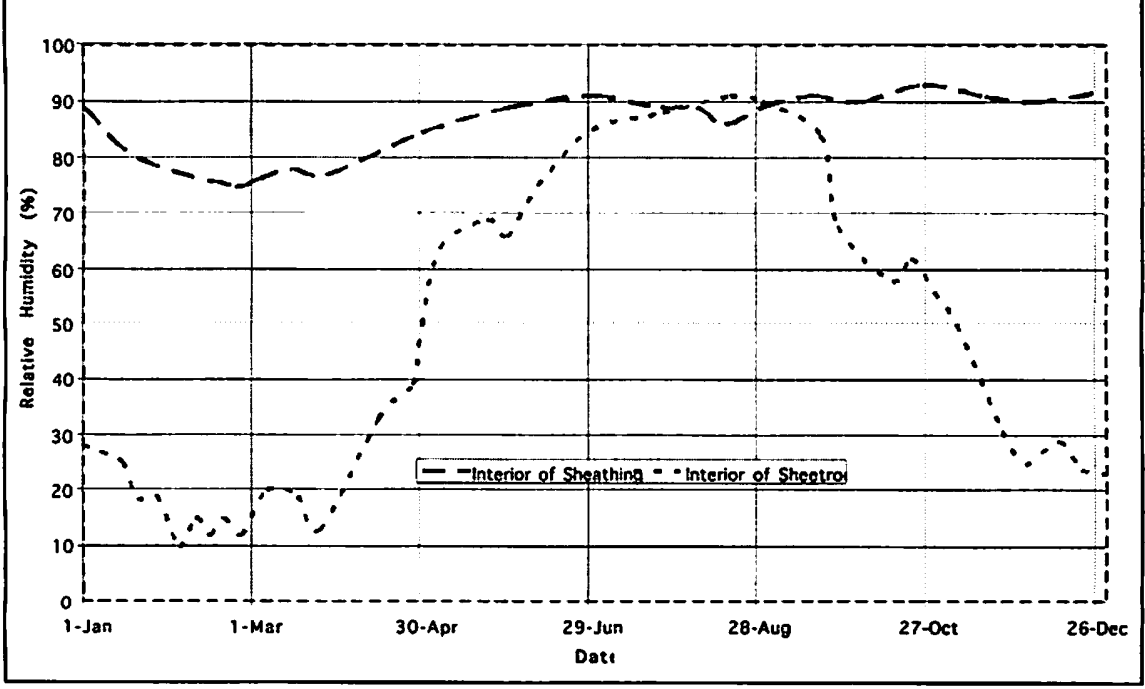

Average Relative Humidity in Wall Cavity 
window/door locations. The discontinuities however, are real and are demonstrated points of entry of moisture from the interior and from the exterior. Sealing of the vapor barrier at the penetrations in the building envelope was not commonly done in the upper Midwest until after 2000. The requirement to seal the vapor barrier at window locations was not well written in the energy code. The energy code requires that a "vapor retarder must be installed between the interior surface and the winter design condition dew point location within each building envelope surface to prevent diffusion of moisture into thermal insulation". This requirement can be fulfilled by painted interior surfaces however, it is commonly accomplished with poly sheeting located between the gypsum wall board and the studs on the warm side of the wall cavity. The energy code also required the following;
"Air leakage barrier:" "A barrier against air leakage must be installed to prevent the leakage of moisture-laden air from the con- ditioned space into the building envelope." "Rim joists, band joists and where floor joists or trusses meet the building envelope must be sealed to prevent air leakage. EXCEPTION: Not required for category II buildings."

As an example of non uniformity in implementation, the requirements for category I were optional in the State of Minnesota until April 13th 2000 and thus the poly vapor barrier/air infiltration barrier was not sealed to the windows or other penetrations until after that time. It is not known on a state by state, municipality or juristictional basis across the U.S. when or with which amendments these requirements were implemented. Also, confusion exists with contractors and code officials as to interpretation of air infiltration barrier and vapor barrier. The air infiltration barrier is commonly understood by many to be provided by house wrap (weather resistive barrier). The most deteriorated areas normally appear at and below window locations due to discontinuities at these locations. The code requirements are poorly expressed and therefore not understood and consequently not implemented by contractors nor required by the building officials.

\section{Building Materials and Moisture Content;}

Moisture content in the sheathing on the exterior of the wall cavity was modeled using the material wood fiberboard at the Minneapolis, Minnesota latitude and longitude approximately 44 degrees north latitude with a $2 \times 6$ standard stud wall construction and fiberglass fill insulation. The graph displays water content in sheathing expressed as pounds per cubic foot. Days begin with January 1 as day 0 . The analysis results in moisture contents expressed as a percentage in the range of approximately 33 percent at the end of the annual cycle. In the mid winter period water content ranges from approximately 16 percent to 
approximately 27 percent. The data reflect percentages above 20 percent, as shown on the graph. It is commonly accepted that at moisture content levels chronically above 20 percent deterioration (rotting) of wood products will occur. It is interesting to note that the moisture content in sheathing continues to increase throughout the period.

Tests conducted over a period of many weeks on the fiberboard product determined the dry bulk density to be 18.5 pounds per cubic $\mathrm{ft}$. The product is slow to saturate requiring approximately 2 weeks when completely submerged under approximately 4 inches of water. The product requires over 4 weeks to dry when completely exposed in 70 degree air at relative humidity levels of approximately 35 percent. This product is a common sheathing product and is approved by all of the code committees which were involved in the development of the energy code. Aspects of vapor transmission rate are not reported and appear to have been ignored in the approval of the products which would certainly be utilized in construction of wood frame structures under provisions of the energy code. Other approved sheathing products in common use include oriented strand board (OSB). This product is essentially water proof and has a vapor transmission rate approximately that of polyethylene vapor barrier and hence would qualify as vapor barrier. The product functionally acts as an exterior vapor barrier on cold sides of walls. The vapor transmission rate is the critical parameter with respect to drying. This correlates with field observations typically around window areas and areas with penetrations which combine exterior or "bulk water" with the interior moisture that over time the sheathing becomes increasingly wet. The common wettest areas and most deteriorated (rotted) sheathing

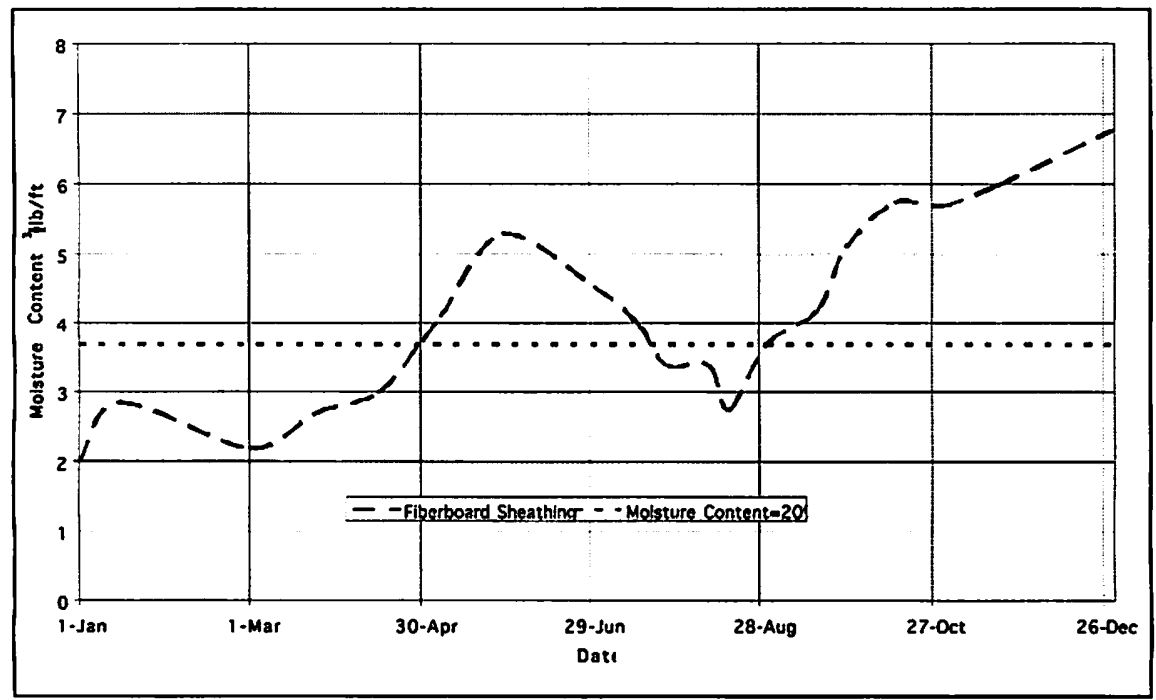

Moisture Content of Fiberboard Sheathing 
and framing typically appear at lower window corners. These areas are subject to much greater heat loss due to geometry which provides energy loss at the notch areas, and greater stud density and hence lower insulation values.

These materials' aspects and properties such as water penetration resistance and vapor transmission rate appear to have been ignored by the code writers. The result is a conflict provided by the energy code, building code and products which are approved by the code committees for sheathing in structures built under the provisions of the codes. No exclusion of these approved sheathing products in construction of wall assemblies under the provisions of the energy code appears. Liability for damage to structures constructed with these materials is typically attributed to contractors.

\section{HVAC}

HVAC is typically configured with circulating fan systems using ductwork. Ductwork is installed within the framing of the structure. Variations in framing have corresponding effects with respect to leakage from the ductwork entering wall cavities. Construction materials including the use of open web wood frame floor trusses have resulted in creating plenums throughout floor areas and in some cases ceiling areas. The effect therefore is to pressurize floor areas and pressurize wall areas. Leakage of moisture laden air under pressure into wall areas results from electrical penetrations and other penetrations including gaps in the framing. Measurements of pressures in residential ductwork typically find pressures in the order of magnitude of 0.1 inch water column static pressure in the supply ducts. Measurements of static pressure in the habitable spaces in wood frame structures have found values in the range of .01 inches negative pressure with respect

to the exterior pressure. This is typical in northern latitudes resultant to the expelling of exhaust gases from the building. Leakage from ductwork in residential wood frame construction enters the framing as described above. The relative pressure between the floor spaces/plenum is approximately one order of magnitude

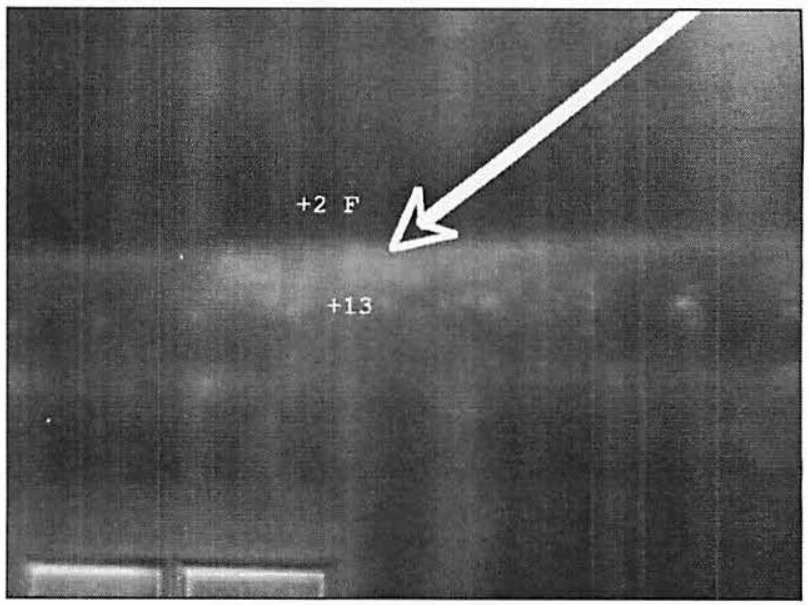

Infrared image depicting area of insulated rim joist showing effects of HVAC leakage. 
greater than the habitable area. As a consequence, the overall slight negative pressure within the building habitable spaces does not result in air infiltration at the joist spaces but rather air exfiltration from pressurization of the joist spaces. The interior atmosphere in winter months has almost uniformly much higher relative humidity levels than the exterior due to the sharp temperature differentials. As a consequence, pressurized, moisture laden air enters the wall cavities. Sealing of ductwork is not required by the codes at static pressures below 0.25 inches water column in the supply ducts. Residential systems observed by this office have always been below this static pressure and therefore excluded from the requirement of sealed ductwork. Consequently, the effects of the high insulation levels in the walls and un-sealed ductwork have resulted in a conflict with the result that moisture laden air is driven into the building envelope.

During multiple field inspections where penetrations are cut through the exterior of the building envelope through the siding and sheathing at rim joist levels, the condition of air leakage from the interior to the exterior has been readily observed without instruments. The volume of air movement is large as compared with the relatively small volume in the wall cavities. Exteriors of the wall cavities are not sealed as compared with the interiors which require vapor barriers and therefore provide air flow and continuous supply of moisture. Consequently, there is an overall exfiltration into the wall cavity of moisture laden air as pressure relief through the exterior occurs. The relatively cold surfaces of the exterior sheathing level within the wall cavity provide surfaces upon which the moisture condenses. The effects of leakage in ductwork appear to have been under estimated or ignored by the promulgators of the energy code with unforeseen adverse effects.

\section{Ceiling Penetrations and Wall Penetrations}

Electrical outlets in walls are required under category I requirements of the energy code to be sealed but not in category II. As noted above, a delay in implementation of category I requirements existed. Light fixtures in ceiling cavities in the heated portions of the structure such as lower levels and main levels of two story homes where no air barrier is required need not be sealed. However, moisture laden air passes through these penetrations and travels to the interior surface of the cold rim joist and condenses. Under category II, sealing of the rim area was not required. These areas, however, were required to be insulated and were typically insulated with fiberglass batt insulation stuffed into the rim areas at the joist locations. This construction resulted in an insulated rim area which was fully permeable to air migration. The presence of the insulation maintained the rim joist relatively cold creating a condensing surface. The condensate forms then drains into the wall cavity resulting in wet sheathing. This condition can be particularly acute in unfinished basements in "walk out" style construction having full height wood frame walls. The adverse effect 
in the energy code of exclusion of the requirement for sealing of ceiling light fixtures while permitting unsealed rim areas and penetrations in heated ceiling/floor areas was apparently unforeseen.

\section{Make Up Air Supply/Combustion Air and HRV Ducts;}

Requirements in the Uniform Mechanical Code for make up air had been implemented since the early 1980s. This is normally provided with a hooded and screened inlet penetrating the exterior typically at the main floor level rim area. Normally, an insulated flexible duct is installed which is required by code to discharge near floor level near the furnace or gas appliance such as water heaters. Similar inlet hoods appear associated with Heat Recovery Ventilators (HRV's). In the field, it is found that the make up air ducts, particularly at areas which are wooded or forested, are commonly plugged on the exterior screen. The relatively fine mesh of the screen in the hood stops incoming seeds and airborne debris, building a relatively thick layer of material which functionally blocks the make up air supply. The result is to increase the relative differential pressure within the structure and to reduce the continuous supply of cold dry air. The reduced supply of dry air into the building results in increased relative humidity level in the interior which then migrates or diffuses into the rim areas and wall cavities as described above. The air inlet screens require regular inspection and maintenance. These elements were uncommon prior to implementation of the energy code. Few seem to be aware of the significance and contributory aspects to the moisture problem due to failure to maintain the air inlet screens.

\section{Wall Cavity Ventilation}

Review of major building codes published over a period of many years has found no provision for ventilation of wall cavities. The codes including IRC, IBC and UBC have for many years required ventilation of attic spaces, crawl spaces and under floor areas. The typical structure can be viewed theoretically as a rectangular box with an attic and under floor space and 4 walls. The conditions of cold dry air on the exterior of the element are essentially the same on all 6 sides of the element. The codes require ventilation of only 2 sides of the element. Consequently, 4 sides of the element (walls) are not ventilated. The need for ventilation of wall cavities was not seen in the R-13 wall construction as heat flux and ventilation were sufficient to prevent moisture problems in the envelope. The model energy code requirements for vapor barriers and selective sealing of interior surfaces through various mechanisms including sealed electrical outlets, lights and rim joists has effectively blocked ventilation from the wall cavity to the interior. Modern construction materials and requirements for weather resistive barriers (house wrap) on the exterior combined with sheathing materials which are essentially vapor barriers due to very low vapor transmission rates has now resulted in the condition which requires ventilation of the wall cavity. The energy code requirements have created conditions which require ven- 
tilation, yet to date there are no requirements in US building codes or the energy code for ventilation of wall cavities.

\section{Summary}

Introduction of the Model Energy Code in conjunction with the building codes has resulted in substantially increased insulation levels and highly sealed or partially sealed interior surfaces. Combined with unsealed ductwork in HVAC systems and increased sealing of the exterior surfaces of the building envelope caused by application of weather resistive barriers and new building materials, the aggregate effect is to produce a building envelope which is highly intolerant of moisture. The combined effects of the energy code interposed with the building codes and materials approved for use in wall construction by the code committees with no requirements for ventilation of wall cavities has resulted in conditions which drive moisture laden air into wall cavities which condenses and accumulates. The conditions have resulted in widespread and rapid deterioration of the building envelope with rotting of sheathing and framing members.

Engineers providing expert services in the realm of construction defects litigation and moisture intrusion and accumulation would be well advised to familiarize themselves with the Model Energy Code and relevant areas of the Building and Mechanical Codes. The causes of deterioration in the various areas of the building envelope result from sources of moisture and entrapment of moisture caused by code provisions, approved construction methods and approved materials. Close scrutiny of the affected areas of the building envelope and analysis of the various causes of distress in those areas requires analysis of code provisions. The engineer making such an analysis must also be versed in the scopes of work of the various subcontractors in order to provide an accurate assessment which can assist those determining liability. 